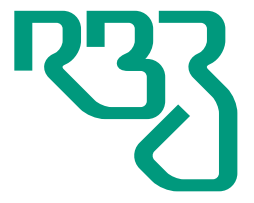

\section{Revista}

Brasileira de

Zootecnia

Brazilian Journal of Animal Science

ISSN 1806-9290

www.rbz.org.br

\title{
Effects of PSMA1 on the differentiation and lipid deposition of bovine preadipocytes
}

\author{
Sheng Li ${ }^{1}$ iD, Chengzhen Chen ${ }^{1^{*}}$ (iD), Hao Jiang ${ }^{1,2}$ (iD), Jiabao Zhang ${ }^{1}$ (iD, Qian \\ Zhou $^{1}$ (iD), Yan Gao ${ }^{1}$ iD, Bao Yuan ${ }^{1}$ (iD, Mingjun Zhang ${ }^{1}$ (iD \\ ${ }^{1}$ Jilin University, College of Animal Sciences, Department of Laboratory Animals, \\ Changchun, Jilin, China. \\ ${ }^{2}$ Chungbuk National University, Department of Animal Science, Cheongju, Chungbuk, Korea.
}

\author{
*Corresponding author: \\ 1651001215@qq.com \\ Received: November 14, 2018 \\ Accepted: July 13, 2019 \\ How to cite: Li, S.; Chen, C.; Jiang, H.; Zhang, J.; \\ Zhou, Q.; Gao, Y.; Yuan, B. and Zhang, M. 2019. \\ Effects of PSMA1 on the differentiation and lipid \\ deposition of bovine preadipocytes. Revista \\ Brasileira de Zootecnia 48:e20180229. \\ https://doi.org/10.1590/rbz4820180229 \\ Copyright: This is an open access article \\ distributed under the terms of the \\ Creative Commons Attribution License \\ (http://creativecommons.org/licenses/by/4.0/), \\ which permits unrestricted use, distribution, \\ and reproduction in any medium, provided the \\ original work is properly cited.
}

\begin{abstract}
In this study, our goal was to clarify the role of proteasomal subunit $\alpha-1$ (PSMA1) in both the differentiation of preadipocytes and the accumulation of lipids in adipocytes. Preadipocytes from healthy one-day-old calves were collected, isolated, and cultured in vitro. The expression pattern of the PSMA1 gene was explored during the differentiation of bovine preadipocytes firstly. Then, the expression of the PSMA1 gene was inhibited by transfection of a chemically synthesized small interfering RNA (siRNA) before differentiation. After induction of differentiation, the mRNA levels of key regulating genes involved in preadipocyte differentiation and the lipid content of mature adipocytes with and without inhibition of PSMA1 were detected by qRT-PCR and oil red 0 staining, respectively. The data showed that PSMA1 mRNA was differentially expressed during the differentiation of bovine preadipocytes under normal culture conditions in vitro. The expression level of peroxisome proliferator-activated receptor gamma (PPAR $\gamma)$, CCAAT enhancer-binding protein alpha (C/EBP $\alpha$ ), and lipoprotein lipase (LPL) were significantly decreased in the transfected PSMA1-siRNA group compared with those in the control group, and the mRNA levels of the preadipocyte factor-1 (Pref-1) were significantly upregulated in the transfected PSMA1-siRNA group compared with those in the control group. In addition, significantly fewer lipid droplets were formed by adipocytes transfected with PSMA1-siRNA than by the negative control group (adipocytes transfected with NC-siRNA). Therefore, PSMA1 plays an important role in differentiation and lipid deposition.
\end{abstract}

Keywords: gene expression, siRNA, transfection, triglyceride

\section{Introduction}

As the main organ of energy storage in animal bodies, adipose tissue plays an important role in regulating metabolism. Moreover, fat (or fatty acid) content has an important influence on meat quality and flavor (Lee et al., 2010; Corino et al., 2008). In recent years, the effects of molecular genetics, management, nutrition, and feeding methods on fat content have been studied (Ceciliani et al., 2015; Koltes et al., 2017), and studying the biological process of bovine fat formation from the perspective of molecular genetics can save costs and be more effective (Mehta et al., 2019).

Proteasome subunit alpha type 1 (PSMA1) is a member of the 20S proteasome $\alpha$ subunit. The $20 \mathrm{~S}$ proteasome core is responsible for dissociating the protein substrate. PSMA1 is an important component of the proteasome and plays an important role in regulating the physiological state of the body and the occurrence of cancer (Lee and Ryu, 2017; Wang et al., 2018). Recent studies have found that PSMA1 is differentially expressed during fatty acid metabolism and lipid production (Seong et al., 
2016) and in the non-alcoholic fatty liver (Wang et al., 2016) and an obese rat model (Sakamuri et al., 2016). This pattern suggests that PSMA1 may play an important role in regulating fat formation and metabolism. However, the specific physiological role of PSMA1 in preadipocytes and whether it can affect the differentiation, lipid generation, and lipid deposition of preadipocytes are rarely studied.

In adipose tissue, many cytokines, including preadipocyte factor-1 (Pref-1), peroxisome proliferatoractivated receptor gamma (PPAR $\gamma$ ), lipoprotein lipase (LPL), and CCAAT enhancer-binding protein alpha (C/EBP $\alpha$ ), can regulate preadipocyte differentiation, lipid accumulation, and adipogenesis (Issemann and Green, 1990; Lim et al., 2015). Preadipocyte differentiation requires exogenous adipogenic stimulators such as glucocorticoid and insulin (Zebisch et al., 2012). Once preadipocytes begin to transform into adipocytes, some transcription factors, such as C/EBP $\alpha$, are activated to induce the expression of metabolic genes and adipokines (Lefterova and Lazar, 2009). Pref-1, PPAR $\gamma$, LPL, and C/EBP $\alpha$ all play a key role with different regulatory effects (Guo and Liao, 2000). Pref-1 is a member of the EGF-like gene family homeobox that inhibits the differentiation of preadipocytes (Smas et al., 1994; Smas et al., 1997). PPAR $\gamma$ mainly plays a role in regulating adipocyte differentiation, lipid metabolism, glucose homeostasis, and insulin sensitivity (Chawla et al., 1994; Tontonoz et al., 1998); it is known as an intrinsic determinant of adipocyte differentiation and can initiate the expression of adipose tissue-specific genes (Gregoire et al., 1998).

There is a correlation between the expression of LPL and the intermuscular fat content in the longissimus muscle of beef cattle (Li et al., 2017a), and its activity also affects the intermuscular fat content and meat quality (Soret et al., 2016). C/EBP $\alpha$ regulates adipogenesis by assisting lipogenesis gene expression and influencing glucose uptake in adipocytes, and it plays an important role in different stages of preadipocyte differentiation (Madsen et al., 2014; Zaini et al., 2018). In addition, other studies have shown that many cytokines or endogenous chemicals can affect the differentiation and lipid accumulation of preadipocytes (Chen et al., 2016; Ruiz-Ojeda et al., 2016). However, whether these key cytokines and genes are affected by PSMA1 is still unclear.

Therefore, this study aims to explore the effect of PSMA1 on the differentiation and lipid deposition of bovine preadipocytes. We reveal the effect of PSMA1 on fat formation at the gene level and provide a theoretical basis for the improvement of beef meat quality.

\section{Material and Methods}

In this study, three healthy one-day-old calves that did not eat colostrum were selected. All experiments were conducted in strict accordance with the recommendations of the local Guidelines for the Care and Use of Laboratory Animals (IACUC-20170355) in Changchun, Jilin Province of China $\left(43.919825^{\circ} \mathrm{N}, 125.273824^{\circ} \mathrm{E}\right)$.

All chemicals and reagents were purchased from Sigma-Aldrich (St. Louis, MO, USA), unless expressly stated otherwise.

Preadipocytes were obtained as previously reported (Hong et al., 2006; Karagiannides et al., 2006; Gupta et al., 2008; Nomura et al., 2011). Briefly, the bovine mesentery was removed in a sterile environment, placed in phosphate buffer saline (PBS) containing a 5\% penicillin/streptomycin mixture (Hyclone Laboratories Inc, Utah, USA), and flushed gently with a pipette to remove the attached blood. Two layers of the mesentery were separated by using ophthalmic forceps, and the adipose tissue attached to the mesentery was separated and collected. After being washed several times with a pipette in PBS, the adipose tissue was placed in a 10-mL centrifuge tube and cut into $1-\mathrm{mm}^{3}$ pieces with ophthalmic scissors. Collagenase (GIBCO, NY, USA) was added, and the adipose tissue was digested at $37^{\circ} \mathrm{C}$ in a water bath for $1.5 \mathrm{~h}$, filtered through 80 mesh and 200 mesh cell strains, and centrifuged at $1500 \times g$ for $15 \mathrm{~min}$. The cell pellet was mixed with complete medium (DMEM/F12 medium containing 10\% FBS and 1\% penicillin/streptomycin) and placed in a cell culture flask. The complete medium was changed every two days after the cells became adherent.

R. Bras. Zootec., 48:e20180229, 2019 
Images of cells were obtained using a stereoscopic microscope (Olympus, Tokyo, Japan) (GálvezPrieto et al., 2008; Chen et al., 2013).

The bovine preadipocytes were seeded into six-well plates. When the cells grew to 0.6 confluence, the complete medium was changed to basic DMEM/F12 medium without serum and double antibodies. After $6 \mathrm{~h}$ of incubation in DMEM/F12 medium, the cells were prepared for transfection. For transfection of cells, the original culture medium was first removed from the cell culture well, and $5 \mu \mathrm{L}$ of the transfected culture medium, Opti-MEM medium (Life Technologies, Inc., MD, USA) with $5 \mu \mathrm{L}$ of Lipofectamine $^{\mathrm{TM}} 2000$ (Life Technologies), and 100 pmol siRNA (GenePharma, Shanghai, China) was prepared. Next, $1.9 \mathrm{~mL}$ of complete medium was added to the culture wells, and the components were gently mixed. After $48 \mathrm{~h}$ of cultivation, the culture medium was replaced.

The siRNA sequences used were as follows: siRNA696 sense strand - 5'-GGUAAAGACUUGGAGUUUATT-3'; antisense strand - 5'-UAAACUCCAAGUCUUUACCTT-3' for transfection group; negative control (NC) sense strand - 5'-UUCUCCGAACGUGUCACGUTT-3'; and NC antisense strand - 5'-ACGUGACACGUUCGGAGAATT-3' for negative control group (no gene expression were changed with NC-siRNA transfection).

Briefly, the isolated primary preadipocytes were inoculated into culture medium in $25 \mathrm{~cm}^{2}$ cell culture flasks. After the cells were grown to a confluence of $60 \%$ or $48 \mathrm{~h}$ after transfection (due to requirements of the experiment), the original medium was removed, and the induction medium $(10 \mu \mathrm{g} / \mathrm{mL}$ insulin, $33 \mu \mathrm{mol} / \mathrm{L}$ calcium pantothenate, and $17 \mu \mathrm{mol} / \mathrm{L}$ transferrin in $50 \mathrm{~mL}$ complete medium) was added to induce the bovine preadipocytes. This medium was changed every two days. The time was recorded as induction day 0 . Images were obtained using a stereoscopic microscope (Olympus).

To clarify the expression pattern of PSMA1 during the differentiation of preadipocytes, we collected cells at $0,4,8$, and 12 days after the induction of their differentiation into bovine preadipocytes to detect the mRNA expression levels of PSMA1 at different time points. Then, we collected bovine cells on day 4 after the transfection of PSMA1-siRNA and NC-siRNA to detect the mRNA expression levels of Pref-1, PPAR $\gamma$, LPL, and C/EBP $\alpha$. Cells were digested with 0.0025 trypsin, and total RNA was extracted using Tripure Isolation Reagent (Roche, Manheim, Germany). Total RNA was reverse transcribed into cDNA using a reverse transcription kit, and the resultant cDNA was used as a template for qRT-PCR. The qRT-PCR reaction system consisted of $10 \mu \mathrm{L}$ of RealMasterMix (Tiangen, Beijing, China), $0.5 \mu \mathrm{L}$ each of the upstream and downstream primers $(10 \mathrm{pmol} / \mu \mathrm{L}$, all sequences shown in Table 1), $2 \mu \mathrm{L}$ of the c-DNA template, and $7 \mu \mathrm{L}$ of $\mathrm{ddH}_{2} \mathrm{O}$. The qRT-PCR conditions were as follows: predegeneration at $95^{\circ} \mathrm{C}$ for $5 \mathrm{~min}$ and 40 cycles of $95^{\circ} \mathrm{C}$ for $20 \mathrm{~s}, 60^{\circ} \mathrm{C}$ for $20 \mathrm{~s}$, and $72{ }^{\circ} \mathrm{C}$ for $20 \mathrm{~s}$. The mRNA expression level was analyzed by an Eppendorf Mastercycler (Eppendorf, Hamburg, Germany) with relative quantitation (2 $2^{-\Delta \Delta \mathrm{ct}}$ method) (Pfaffl et al., 2002) with GAPDH as the standard. Three biological duplications were performed following the same procedure with three calves, and three technical repetitions were performed for each biological repetition. The mRNA expression level

Table 1 - Primers used for real-time PCR

\begin{tabular}{ll}
\hline Gene & \\
\hline PSMA1 & Fequence (5' to $3^{\prime}$ ) \\
& Reverse: TCCAAGTAAGTACGAGCTGATTGA \\
LPL & Forward: GTACAAGAGGGAACCGGACTC \\
& Reverse: AGGAGAAAGGCGACTTGG \\
Pref-1 & Forward: AAGCACCGGCAGACAAGA \\
& Reverse: CAGAGGAGGGAGTCGTCAGTA \\
PPAR $\gamma$ & Forward: GCGAGGAGGACGAAGCGAAG \\
& Reverse: GCGCAGGCGGTCATTGTC \\
$\beta$-actin & Forward: AGGTCATCACCATCGGCAATG \\
& Reverse: ACAGCACCGTGTTGGCGTAGAG
\end{tabular}


of the three repeated experiments was first calculated using the $2^{-\Delta \Delta c t}$ method, and then the value of the relative expression level in the control group (the transfected PSMA1-siRNA negative control group at day 0 ) was set to 1 according to the mean value and standard deviation. Finally, the relative mRNA expression levels of the other groups were calculated.

Oil red 0 staining was performed on day 4 after the transfection of bovine preadipocytes. In cell culture plates, the negative control cells and the transfected cells were fixed with $10 \%$ neutral formalin for $30 \mathrm{~min}$, washed with PBS, and stained with an Oil Red Staining Kit (Solarbio, Beijing, China). The oil red 0 staining solution was removed, and then the cells were washed three times with PBS. After the stained cells were fixed in isopropanol for $15 \mathrm{~min}$, images were obtained using a stereoscopic microscope (Olympus) (Puri et al., 2012; Kim et al., 2013), and absorbance values were recorded using a visible spectrophotometer at a wavelength of $490 \mathrm{~nm}$. The triglyceride content was determined according to instructions of the Triglyceride Detection Kit (E1012, Applygen, Beijing, China). Triglyceride detection was performed on the fourth day after PSMA-1 siRNA and NC-siRNA transfection.

All statistical analyses were performed using SPSS version 22.0 (IBM, IL, USA) software. Data obtained from two groups were compared using the $t$ test. Differential PSMA1 mRNA expression levels on different days were analyzed using a one-way ANOVA. The following statistical model used was as follows:

$$
Y_{i j}=\mu+a_{i}+e_{i j}
$$

in which $Y_{i j}=$ observed variable, $\mu$ = overall mean, $a_{i}=$ the sample processing effect of the cell culture time i $\left(1,2,3\right.$, and 4 represent days $0,4,8$, and 12, respectively), and $e_{i j}=$ random error. Significant differences were determined using a protected Tukey's test after one-way ANOVA. Significant differences are represented with $*(\mathrm{P}<0.05)$ and ${ }^{* *}(\mathrm{P}<0.01)$.

\section{Results}

The isolated bovine preadipocytes were cultured for $24 \mathrm{~h}$ and began to adhere. After $48 \mathrm{~h}$, they began to divide and grow in large numbers and gradually developed a stable, long, spindle-shaped cell morphology (Figure 1A, B). However, the expression levels of PSMA1 in bovine preadipocyte
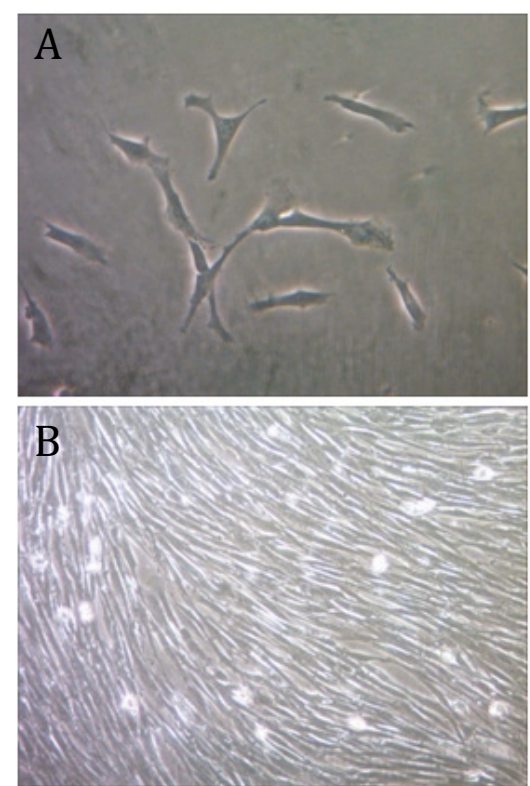

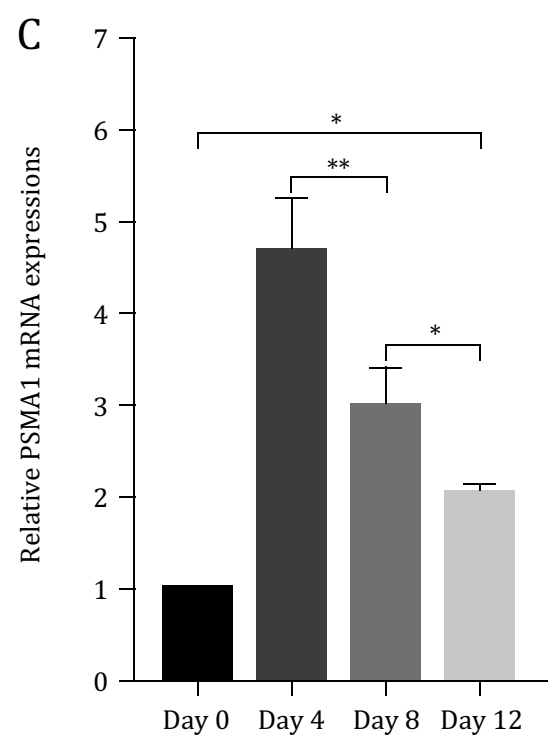

A and B: fusiform preadipocytes cultured for 24 and 192 h, respectively (200 X). C: changes in PSMA1 mRNA expression of mature adipocytes after induction for differentiation.

Figure 1 - Bovine preadipocytes and relative mRNA expression of PSMA1 in preadipocytes at 0, 4, 8 and 12 days of differentiation. 
differentiation at days $0,4,8$, and 12 first increased and then decreased (the relative expression of PSMA1 was expressed as mean $\pm S D$; the expression levels were $1.000 \pm 0.000,4.698 \pm 0.563$, $3.012 \pm 0.389$, and $2.059 \pm 0.057$, respectively), and the expression was the highest on the fourth day following the induction of differentiation (Figure 1C). The expression on the 12th day following induction was significantly decreased compared with that on the fourth day but was still significantly higher than that on day 0 .

Since the expression level of PSMA1 was the highest at four days after induction under normal culture conditions, the key regulatory factors (Pref-1, PPAR $\gamma, \mathrm{C} / \mathrm{EBP} \alpha$, and LPL) of preadipocyte differentiation and lipid deposition in preadipocyte that was transfected with PSMA1-siRNA changed. Their mRNA levels were tested on the fourth day following the induction of differentiation (Figure 2). Compared with those in the negative control group, the expression levels of PPAR $\gamma, \mathrm{C} / \mathrm{EBP} \alpha$, and LPL, which promote the differentiation of adipocytes and lipid deposition, were significantly decreased in the transfected PSMA1-siRNA group, and the mRNA levels of the differentiation factor Pref-1 were significantly upregulated (the relative expression levels of PPAR $\gamma, \mathrm{LPL}, \mathrm{C} / \mathrm{EBP} \alpha$, and Pref- 1 in the transfected PSMA1-siRNA group were $0.258 \pm 0.041,0.353 \pm 0.076,0.765 \pm 0.080$, and $1.572 \pm 0.132$, respectively; the expression levels of these mRNA in the negative control group were all set to $1.000 \pm 0.000$ ). Thus, transfection with PSMA1-siRNA may inhibit preadipocyte differentiation and lipid deposition.

After the siRNA-induced interference was confirmed to be effective, we transfected siRNA into preadipocytes by Lipofectamine ${ }^{\mathrm{TM}} 2000$ and then cultured the cells in induction medium. When the induction medium was changed, it was recorded as day 0 , and oil red 0 staining was performed on the 12th day. There were significantly fewer lipid droplets formed by adipocytes transfected with PSMA1-siRNA than those in the NC group (Figure 3), which indicates that PSMA1 inhibits lipid droplet formation in adipocytes (Figure 3A-D). At the same time, the triglyceride content in the PSMA1-siRNA transfection group was significantly lower than that in the NC group (the relative triglyceride contents of the NC group and the transfected PSMA1 group were expressed as the mean \pm SD; these values were $1.000 \pm 0.000$ and $0.706 \pm 0.165$, respectively) (Figure $3 \mathrm{E}$ ). These results show that transfection of PSMA1 with siRNA inhibits the production and accumulation of triglycerides in mature adipocytes.

\section{Discussion}

Unlike porcine and mouse cells, the growth and differentiation of bovine preadipocytes was relatively slow. Porcine and mouse preadipocytes differentiated into more mature adipocytes after two days of

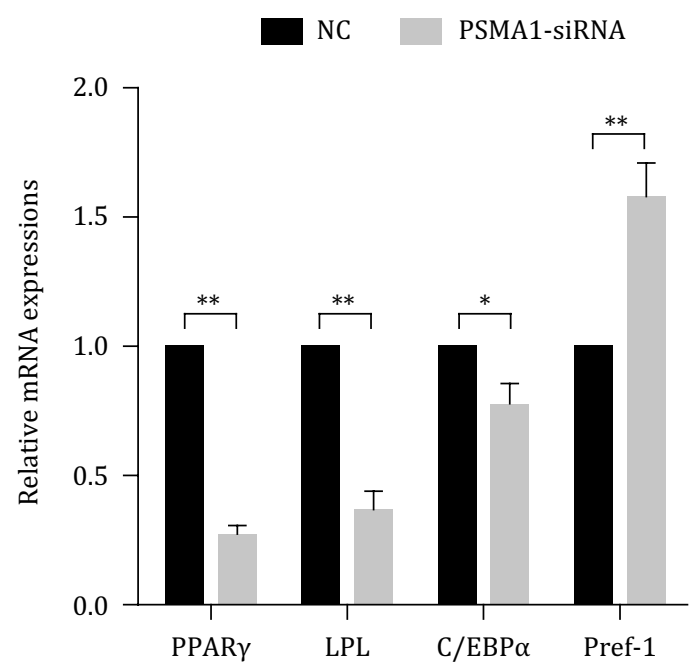

Differential gene mRNA expression levels obtained from negative control $(\mathrm{NC})$ and PSMA1-siRNA groups were compared by the $t$ test. Figure 2 - Changes in Pref-1, PPAR $\gamma, \mathrm{C} / \mathrm{EBP} \alpha$, and LPL mRNA expression after inhibition of PSMA1. 

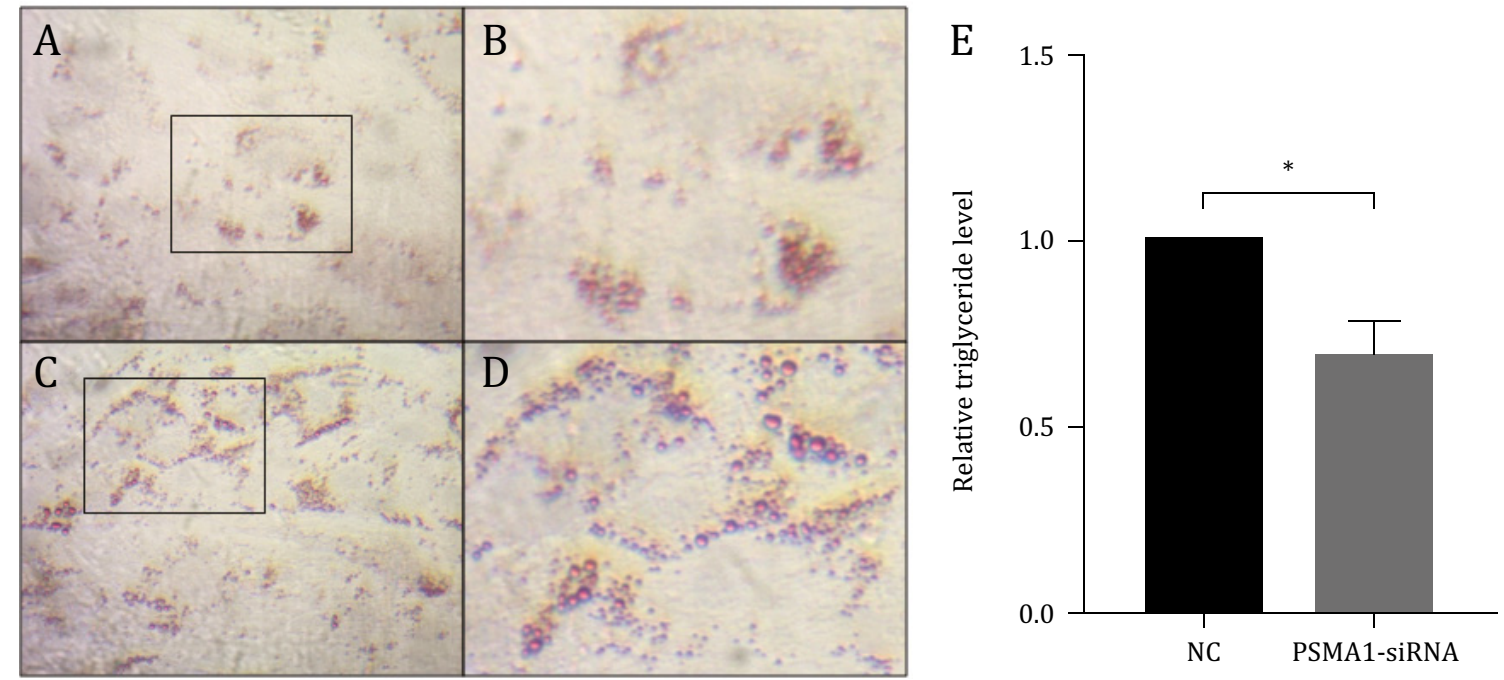

A and $\mathrm{C}$ show the lipid deposition in the adipocytes of negative control (NC) group and PSMA1-siRNA group under the microscope (200 X), respectively; $\mathrm{B}$ and $\mathrm{D}$ are the enlarged image of selected area from $\mathrm{A}$ and $\mathrm{C}$, respectively; $\mathrm{E}$ is the relative triglyceride content level in the $\mathrm{NC}$ and PSMA1-siRNA groups.

Differential relative triglyceride content obtained from NC and PSMA1-siRNA groups were compared by the $t$ test.

Figure 3 - Effects of PSMA1 inhibition on lipid deposition of bovine adipocytes.

incubation (Wang et al., 2010; Shi et al., 2014). However, only small numbers of bovine preadipocytes were observed on the second day in this study. The cells began to gradually differentiate and adopted a long, spindle-like shape after seven days of incubation. This might be one of the reasons why bovine intermuscular fat exhibits slower lipid deposition than the intermuscular fat of mice and pigs (Kratchmarova et al., 2002; Luo et al., 2008).

Similar to the results of other studies, bovine preadipocytes began to differentiate into mature adipocytes, accumulate large amounts of triglycerides, and form lipid droplets two to four days after induction (Hirai et al., 2007; Yang et al., 2017). Our study showed that the expression of PSMA1 after the differentiation of bovine preadipocytes first increased and then decreased, and the expression of PSMA1 was the lowest on the initial day of the experiment. Over time, the expression of PSMA1 reached its highest value at day 4 after induction and then gradually decreased. During this process, the proportion of undifferentiated preadipocytes gradually decreased, while the proportion of differentiated mature adipocytes and the intracellular triglyceride content gradually increased, suggesting that PSMA1 may be involved in the differentiation of bovine preadipocytes.

To clarify the specific role of PSMA1, we first examined the role of PSMA1 in regulating the key factors (PPAR $\gamma, \mathrm{LPL}, \mathrm{C} / \mathrm{EBP} \alpha$, and Pref-1) involved in the differentiation of preadipocytes and lipid deposition in mature adipocytes. Studies have shown that Pref- 1 and PPAR $\gamma$ play important roles in the differentiation of preadipocytes (Yeh et al., 1995; El-Jack et al., 1999; Moon et al., 2002; Kim et al., 2007a; Wang and Sul, 2009). Pref-1 is highly expressed in preadipocytes (Moon et al., 2002). As the cells differentiate, the expression level of Pref- 1 gradually declines. Finally, Pref- 1 is poorly expressed in mature adipocytes (Wang et al., 2006). PPAR $\gamma$ is the major regulator of adipocyte differentiation and gene expression and plays an important role in adipocyte differentiation (Chawla et al., 1994) and can initiate the expression of adipose tissue-specific genes (Gregoire et al., 1998). In this study, the mRNA level of Pref-1 in the PSMA1 inhibition group was significantly higher than that of the control group four days after the differentiation of preadipocytes. This indicates that the inhibition of PSMA1 affects Pref-1 expression. At the same time, the inhibition of PSMA1 also significantly reduced the expression of PPAR $\gamma$. Combined with the biological effects of Pref- 1 and PPAR $\gamma$, this is consistent with some studies that show that PSMA1 potentially regulates the c-Myc signaling pathway (Kulichkova et al., 2010; Li et al., 2017b), Notch3 (Ogura et al., 2003; Zhang et al., 2007), and Pde3b (Hopitzan et al., 
2000; Ogura et al., 2003) to promote the differentiation of bovine preadipocytes by downregulating the expression of Pref- 1 and upregulating the expression of PPAR $\gamma$.

LPL and C/EBP $\alpha$ have important roles in preadipocyte differentiation and cellular lipid accumulation. The expression of these two genes begins with lipogenesis and induces lipoprotein storage and lipid metabolism (Bauer et al., 2015; Rozovski et al., 2016; Glatz and Luiken, 2017; Hu et al., 2018). Consistent with this, the expression of PSMA1 is potentially associated with $\operatorname{LXR} \alpha$, which is the upstream regulator of LPL and C/EBP $\alpha$ (Zhang et al., 2001; Steffensen et al., 2002; Kim et al., 2007b; Han et al., 2009). In this study, the expression levels of LPL and C/EBP $\alpha$ were significantly reduced after PSMA1 was inhibited. In the inhibited group, both the degree of preadipocyte differentiation and the ability of mature adipocytes to accumulate triglycerides were significantly reduced. These results indicated that PSMA1 has a regulatory effect on LPL and C/EBP $\alpha$ and that PSMA1 not only affects adipocyte differentiation but also has a potential effect on lipid production and metabolism in mature adipocytes.

\section{Conclusions}

Inhibition of PSMA1 can decrease the mRNA expression of C/EBP $\alpha$, PPAR $\gamma$, and LPL and enhance the mRNA expression of Pref-1 in preadipocytes, which in turn inhibits the differentiation of preadipocytes into mature adipocytes. Moreover, PSMA1 can also influence the production of triglycerides in mature adipocytes, thereby affecting the ability of adipocytes to deposit lipids.

\section{Conflict of Interest}

The authors declare no conflict of interest.

\section{Author Contributions}

Conceptualization: S. Li, C. Chen, H. Jiang and Q. Zhou. Data curation: S. Li, C. Chen and Q. Zhou. Formal analysis: S. Li, C. Chen and Q. Zhou. Funding acquisition: S. Li, C. Chen, H. Jiang and J. Zhang. Investigation: S. Li and C. Chen. Methodology: S. Li, C. Chen, H. Jiang, J. Zhang, Y. Gao and M. Zhang. Project administration: S. Li and C. Chen. Resources: S. Li and J. Zhang. Software: S. Li, H. Jiang, Y. Gao and B. Yuan. Supervision: S. Li, H. Jiang, J. Zhang and B. Yuan. Validation: S. Li and J. Zhang. Visualization: S. Li and Q. Zhou. Writing-original draft: S. Li. Writing-review \& editing: S. Li, C. Chen, H. Jiang and M. Zhang.

\section{Acknowledgments}

This study was supported by the National Natural Science Foundation of China (31572400 and 31601940), Modern Agricultural Industry Technology System (CARS-37), co-sponsored projects by province and universities (SXGJSF2017-6), and the Science and Technology Project of Jilin Province (20160203014NY and 20170203010NY).

\section{References}

Bauer, R. C.; Sasaki, M.; Cohen, D. M.; Cui, J.; Smith, M. A.; Yenilmez, B. O.; Steger, D. J. and Rader, D. J. 2015. Tribbles-1 regulates hepatic lipogenesis through posttranscriptional regulation of C/EBP $\alpha$. Journal of Clinical Investigation 125:3809-3818. https://doi.org/10.1172/JCI77095

Ceciliani, F.; Soler, L.; Grilli, G.; Marques, A. T.; Giudice, C. and Lecchi, C. 2015. The localization and differential expression of Serum Amyloid A in bovine liver and adipose tissue depots. Veterinary Immunology and Immunopathology 168:35-39. https://doi.org/10.1016/j.vetimm.2015.08.004

Chawla, A.; Schwarz, E. J.; Dimaculangan, D. D. and Lazar, M. A. 1994. Peroxisome proliferator-activated receptor (PPAR) gamma: adipose-predominant expression and induction early in adipocyte differentiation. Endocrinology 135:798-800. https://doi.org/10.1210/endo.135.2.8033830

R. Bras. Zootec., 48:e20180229, 2019 
Chen, T. Y.; Zhang, Z. M.; Zheng, X. C.; Wang, L.; Huang, M. J.; Qin, S.; Chen, J.; Lai, P. L.; Yang, C. L.; Liu, J.; Dai, Y. F.; Jin, D. D. and Bai, X. C. 2013. Endogenous n-3 polyunsaturated fatty acids (PUFAs) mitigate ovariectomy-induced bone loss by attenuating bone marrow adipogenesis in FAT1 transgenic mice. Drug Design, Development and Therapy 7:545-552. https://doi.org/10.2147/DDDT.S45263

Chen, X.; Zhou, B.; Luo, Y.; Huang, Z.; Jia, G.; Liu, G. and Zhao, H. 2016. Tissue distribution of porcine FTO and its effect on porcine intramuscular preadipocytes proliferation and differentiation. PLoS One 11:e0151056. https://doi. org/10.1371/journal.pone.0151056

Corino, C.; Musella, M. and Mourot, J. 2008. Influence of extruded linseed on growth, carcass composition, and meat quality of slaughtered pigs at one hundred ten and one hundred sixty kilograms of liveweight. Journal of Animal Science 86:1850-1860. https://doi.org/10.2527/jas.2007-0155

El-Jack, A. K.; Hamm, J. K.; Pilch, P. F. and Farmer, S. R. 1999. Reconstitution of insulin-sensitive glucose transport in fibroblasts requires expression of both PPARgamma and C/EBPalpha. Journal of Biological Chemistry 274:7946-7951. https://doi.org/10.1074/jbc.274.12.7946

Gálvez-Prieto, B.; Dubrovska, G.; Cano, M. V.; Delgado, M.; Aranguez, I.; González, M. C.; Ruiz-Gayo, M.; Gollasch, M. and Fernández-Alfonso, M. S. 2008. A reduction in the amount and anti-contractile effect of periadventitial mesenteric adipose tissue precedes hypertension development in spontaneously hypertensive rats. Hypertension Research 31:1415-1423.

Glatz, J. F. C. and Luiken, J. J. F. P. 2017. From fat to FAT (CD36/SR-B2): Understanding the regulation of cellular fatty acid uptake. Biochimie 136:21-26. https://doi.org/10.1016/j.biochi.2016.12.007

Gregoire, F. M.; Smas, C. M. and Sul, H. S. 1998. Understanding adipocyte differentiation. Physiological Reviews 78:783-809. https://doi.org/10.1152/physrev.1998.78.3.783

Guo, X. and Liao, K. 2000. Analysis of gene expression profile during 3T3-L1 preadipocyte differentiation. Gene 251:45-53. https://doi.org/10.1016/S0378-1119(00)00192-X

Gupta, V.; Bhasin, S.; Guo, W.; Singh, R.; Miki, R.; Chauhan, P.; Choong, K.; Tchkonia, T.; Lebrasseur, N. K.; Flanagan, J. N.; Hamilton, J. A.; Viereck, J. C.; Narula, N. S.; Kirkland, J. L. and Jasuja, R. 2008. Effects of dihydrotestosterone on differentiation and proliferation of human mesenchymal stem cells and preadipocytes. Molecular and Cellular Endocrinology 296:32-40. https://doi.org/10.1016/j.mce.2008.08.019

Han, C.; Wang, J.; Li, L.; Wang, L. and Zhang, Z. 2009. The role of LXR alpha in goose primary hepatocyte lipogenesis. Molecular and Cellular Biochemistry 322:37-42. https://doi.org/10.1007/s11010-008-9937-8

Hirai, S.; Matsumoto, H.; Hino, N.; Kawachi, H.; Matsui, T. and Yano, H. 2007. Myostatin inhibits differentiation of bovine preadipocyte. Domestic Animal Endocrinology 32:1-14. https://doi.org/10.1016/j.domaniend.2005.12.001

Hong, Y. H.; Ogihara, Y.; Hishikawa, D.; Gotoh, C.; Iga, T.; Suzuki, Y.; Song, S. H.; Nakajima, K.; Kozakai, T.; Sasaki, S. and Roh, S. G. 2006. Molecular cloning and expression analysis of cDNA encoding bovine adipogenin. Animal Science Journal 77:613-619. https://doi.org/10.1111/j.1740-0929.2006.00393.x

Hopitzan, A.; Himmelbauer, H.; Spevak, W. and Castanon, M. J. 2000. The mouse Psma1 gene coding for the $\alpha$-type C2 proteasome subunit: structural and functional analysis, mapping, and colocalization with Pde3b on mouse chromosome 7 . Genomics 66:313-323. https://doi.org/10.1006/geno.2000.6217

Hu, X.; Tang, J.; Hu, X.; Bao, P.; Pan, J.; Chen, Z. and Xian, J. 2018. MiR-27b impairs adipocyte differentiation of human adipose tissue-derived mesenchymal stem cells by targeting LPL. Cellular Physiology and Biochemistry 47:545-555. https://doi.org/10.1159/000489988

Issemann, I. and Green, S. 1990. Activation of a member of the steroid hormone receptor superfamily by peroxisome proliferators. Nature 347:645-650. https://doi.org/10.1038/347645a0

Karagiannides, I.; Kokkotou, E.; Tansky, M.; Tchkonia, T.; Giorgadze, N.; O’Brien, M.; Leeman, S. E.; Kirkland, J. L. and Pothoulakis C. 2006. Induction of colitis causes inflammatory responses in fat depots: Evidence for substance P pathways in human mesenteric preadipocytes. Proceedings of the National Academy of Sciences of the United States of America 103:5207-5212. https://doi.org/10.1073/pnas.0600821103

Kim, K. A.; Kim, J. H.; Wang, Y. and Sul, H. S. 2007a. Pref-1 (preadipocyte factor 1) activates the MEK/extracellular signal-regulated kinase pathway to inhibit adipocyte differentiation. Molecular and Cellular Biology 27:2294-2308. https://doi.org/10.1128/MCB.02207-06

Kim, W. K.; Meliton, V.; Amantea, C. M.; Hahn, T. J. and Parhami, F. 2007b. 20(S)-Hydroxycholesterol inhibits PPAR expression and adipogenic differentiation of bone marrow stromal cells through a hedgehog-dependent mechanism. Journal of Bone and Mineral Research 22:1711-1719. https://doi.org/10.1359/jbmr.070710

Kim, D. H.; Puri, N.; Sodhi, K.; Falck, J. R.; Abraham, N. G.; Shapiro, J. and Schwartzman, M. L. 2013. Cyclooxygenase-2 dependent metabolism of 20-HETE increases adiposity and adipocyte enlargement in mesenchymal stem cell-derived adipocytes. The Journal of Lipid Research 54:786-793. https://doi.org/10.1194/jlr.M033894

Koltes, D. A.; Spurlock, M. E. and Spurlock, D. M. 2017. Adipose triglyceride lipase protein abundance and translocation to the lipid droplet increase during leptin-induced lipolysis in bovine adipocytes. Domestic Animal Endocrinology 61:62-76 https://doi.org/10.1016/j.domaniend.2017.06.001

R. Bras. Zootec., 48:e20180229, 2019 
Kratchmarova, I.; Kalume, D. E.; Blagoev, B.; Scherer, P. E.; Podtelejnikov, A. V.; Molina, H.; Bickel, P. E.; Andersen, J. S.; Fernandez, M. M.; Bunkenborg, J.; Roepstorff, P.; Kristiansen, K.; Lodish, H. F.; Mann, M. and Pandey, A. 2002. A proteomic approach for identification of secreted proteins during the differentiation of 3T3-L1 preadipocytes to adipocytes. Molecular \& Cellular Proteomics 1:213-222. https://doi.org/10.1074/mcp.M200006-MCP200

Kulichkova, V. A.; Tsimokha, A. S.; Fedorova, O. A.; Moiseeva, T. N.; Bottril, A.; Lezina, L.; Gauze, L. N.; Konstantinova, I. M.; Mittenberg, A. G. and Barlev, N. A. 2010. 26S proteasome exhibits endoribonuclease activity controlled by extra-cellular stimuli. Cell Cycle 9:840-849. https://doi.org/10.4161/cc.9.4.10829

Lee, D. and Ryu, K. Y. 2017. Effect of cellular ubiquitin levels on the regulation of oxidative stress response and proteasome function via Nrf1. Biochemical and Biophysical Research Communications 485:234-240. https://doi. org/10.1016/j.bbrc.2017.02.105

Lee, S. H.; Choi, Y. M.; Choe, J. H.; Kim, J. M.; Hong, K. C.; Park, H. C. and Kim, B. C. 2010. Association between polymorphisms of the heart fatty acid binding protein gene and intramuscular fat content; fatty acid composition, and meat quality in Berkshire breed. Meat Science 86:794-800. https://doi.org/10.1016/j.meatsci.2010.06.024

Lefterova, M. I. and Lazar, M. A. 2009. New developments in adipogenesis. Trends in Endocrinology and Metabolism 20:107-114. https://doi.org/10.1016/j.tem.2008.11.005

Li, X. Z.; Yan, C. G.; Yu, J.; Gao, Q. S.; Choi, S. H.; Shin, J. S. and Smith, S. B. 2017a. Dietary whole and cracked linseed increases the proportion of oleic and alpha-linolenic acids in adipose tissues and decreases stearoyl-coenzyme A desaturase, acetyl-coenzyme A carboxylase, and fatty acid synthase gene expression in the longissimus thoracis muscle of Yanbian Yellow cattle. Journal of Animal Science 95:718-726. https://doi.org/10.2527/jas.2016.1050

Li, X. F.; Sun, Y. Y.; Bao, J.; Chen, X.; Li, Y. H.; Yang, Y.; Zhang, L.; Huang, C.; Wu, B. M.; Meng, X. M. and Li, J. 2017b. Functional role of PPAR- $\gamma$ on the proliferation and migration of fibroblast-like synoviocytes in rheumatoid arthritis. Scientific Reports 7:12671. https://doi.org/10.1038/s41598-017-12570-6

Lim, D.; Chai, H. H.; Lee, S. H.; Cho, Y. M.; Choi, J. W. and Kim, N. K. 2015. Gene expression patterns associated with peroxisome proliferator-activated receptor (PPAR) signaling in the longissimus dorsi of Hanwoo (Korean cattle). AsianAustralasian Journal of Animal Sciences 28:1075-1083. https://doi.org/10.5713/ajas.14.0811

Luo, G. F.; Yu, T. Y.; Wen, X. H.; Li, Y. and Yang, G. S. 2008. Alteration of mitochondrial oxidative capacity during porcine preadipocyte differentiation and in response to leptin. Molecular and Cellular Biochemistry 307:83-91. https://doi.org/10.1007/s11010-007-9587-2

Madsen, M. S.; Siersbaek, R.; Boergesen, M.; Nielsen, R. and Mandrup, S. 2014. Peroxisome proliferator-activated receptor gamma and C/EBP alpha synergistically activate key metabolic adipocyte genes by assisted loading. Molecular and Cellular Biology 34:939-954. https://doi.org/10.1128/MCB.01344-13

Mehta, F; Theunissen, R. and Post, M. J. 2019. Adipogenesis from bovine precursors. Methods in Molecular Biology 10:111-125. https://doi.org/10.1007/978-1-4939-8897-6_8

Moon, Y. S.; Smas, C. M.; Lee, K.; Villena, J. A.; Kim, K. H.; Yun, E. J. and Sul, H. S. 2002. Mice lacking paternally expressed Pref-1/Dlk1 display growth retardation and accelerated adiposity. Molecular and Cellular Biology 22:5585-5592. https://doi.org/10.1128/mcb.22.15.5585-5592.2002

Nomura, E.; Toyoda, N.; Harada, A.; Nishimura, K.; Ukita, C.; Morimoto, S.; Kosaki, A.; Iwasaka, T. and Nishikawa M. 2011. Type 2 iodothyronine deiodinase is expressed in human preadipocytes. Thyroid 21:305-310. https://doi.org/10.1089/thy.2010.0068

Ogura, T.; Osawa, H.; Tang, Y.; Onuma, H.; Ochi, M.; Nishimiya, T.; Kubota, N.; Terauchi, Y.; Kadowaki, T. and Makino, H. 2003. Reduction of phosphodiesterase 3B gene expression in peroxisome proliferator-activated receptor $\gamma(+/-)$ mice independent of adipocyte size. FEBS Letters 542:65-68. https://doi.org/10.1016/S0014-5793(03)00339-9

Pfaffl, M. W.; Horgan, G. W. and Dempfle, L. 2002. Relative expression software tool (REST) for group-wise comparison and statistical analysis of relative expression results in real-time PCR. Nucleic Acids Research 30:e36. https://doi.org/10.1093/nar/30.9.e36

Puri, N.; Sodhi, K.; Haarstad, M.; Kim, D. H.; Bohinc, S.; Foglio, E.; Favero, G. and Abraham, N. G. 2012. Heme induced oxidative stress attenuates sirtuin 1 and enhances adipogenesis in mesenchymal stem cells and mouse pre-adipocytes. Journal of Cellular Biochemistry 113:1926-1935. https://doi.org/10.1002/jcb.24061

Rozovski, U.; Hazan-Halevy, I.; Barzilai, M.; Keating, M. J. and Estrov, Z. 2016. Metabolism pathways in chronic lymphocytic leukemia. Leukemia \& Lymphoma 57:758-765. https://doi.org/10.3109/10428194.2015.1106533

Ruiz-Ojeda, F. J.; Rupérez A. I.; Gomez-Llorente, C.; Gil, A. and Aguilera, C. M. 2016. Cell models and their application for studying adipogenic differentiation in relation to obesity: A review. International Journal of Molecular Sciences 17:1040. https://doi.org/10.3390/ijms17071040

Sakamuri, S. S. V. P.; Putcha, U. K.; Veettil, G. N. and Ayyalasomayajula, V. 2016. Transcriptome profiling of visceral adipose tissue in a novel obese rat model, WNIN/Ob \& its comparison with other animal models. Indian Journal of Medical Research 144:409-423. https://doi.org/10.4103/0971-5916.198667

R. Bras. Zootec., 48:e20180229, 2019 
Seong, J.; Yoon, H. and Hong, S. K. 2016. Identification of microRNA and target gene associated with marbling score in Korean cattle (Hanwoo). Genes \& Genomics 38:529-538. https://doi.org/10.1007/s13258-016-0401-y

Shi, X. E.; Li, Y. F.; Jia, L.; Ji, H. L.; Song, Z. Y.; Cheng, J.; Wu, G. F.; Song, C. C.; Zhang, Q. L.; Zhu, J. Y. and Yang, G. S. 2014. MicroRNA-199a-5p affects porcine preadipocyte proliferation and differentiation. International Journal of Molecular Sciences 15:8526-8538. https://doi.org/10.3390/ijms15058526

Smas, C. M.; Chen, L. and Sul, H. S. 1997. Cleavage of membrane-associated pref-1 generates a soluble inhibitor of adipocyte differentiation. Molecular and Cellular Biology 17:977-988. https://doi.org/10.1128/mcb.17.2.977

Smas, C. M.; Green, D. and Sul, H. S. 1994. Structural characterization and alternate splicing of the gene encoding the preadipocyte EGF-like protein pref-1. Biochemistry 33:9257-9265. https://doi.org/10.1021/bi00197a029

Soret, B.; Mendizabal, J. A.; Arana, A. and Alfonso, L. 2016. Expression of genes involved in adipogenesis and lipid metabolism in subcutaneous adipose tissue and longissimus muscle in low-marbled Pirenaica beef cattle. Animal 10:2018-2026. https://doi.org/10.1017/S175173111600118X

Steffensen, K. R.; Schuster, G. U.; Parini, P.; Holter, E.; Sadek, C. M.; Cassel, T.; Eskild, W. and Gustafsson, J. A. 2002. Different regulation of the LXR $\alpha$ promoter activity by isoforms of CCAAT/enhancer-binding proteins. Biochemical and Biophysical Research Communications 293:1333-1340. https://doi.org/10.1016/S0006-291X(02)00390-X

Tontonoz, P.; Nagy, L.; Alvarez, J. G.; Thomazy, V. A. and Evans, R. M. 1998. PPARgamma promotes monocyte/macrophage differentiation and uptake of oxidized LDL. Cell 93:241-252. https://doi.org/10.1016/S0092-8674(00)81575-5

Wang, C.; Chen, Y. L.; Bian, W. P.; Xie, S. L.; Qi, G. L.; Liu, L.; Strauss, R.; Zou, J. X. and Pei, D. S. 2018. Deletion of mstna and mstnb impairs the immune system and affects growth performance in zebrafish. Fish \& Shellfish Immunology 72:5725-580. https://doi.org/10.1016/j.fsi.2017.11.040

Wang, R.; Wang, X. and Zhuang, L. 2016. Gene expression profiling reveals key genes and pathways related to the development of non-alcoholic fatty liver disease. Annals of Hepatology 15:190-199.

Wang, Y.; Hudak, C. and Sul, H. S. 2010. Role of preadipocyte factor 1 in adipocyte differentiation. Clinical Lipidology 5:109-115.

Wang, Y.; Kim, K. A.; Kim, J. H. and Sul, H. S. 2006. Pref-1, a preadipocyte secreted factor that inhibits adipogenesis. The Journal of Nutrition 136:2953-2956. https://doi.org/10.1093/jn/136.12.2953

Wang, Y. and Sul, H. S. 2009. Pref-1 regulates mesenchymal cell commitment and differentiation through Sox9. Cell Metabolism 9:287-302. https://doi.org/10.1016/j.cmet.2009.01.013

Yang, W.; Tang, K.; Wang, Y.; Zhang, Y. and Zan, L. 2017. Melatonin promotes triacylglycerol accumulation via MT2 receptor during differentiation in bovine intramuscular preadipocytes. Scientific Reports 7:15080. https://doi.org/10.1038/s41598-017-12780-y

Yeh, W. C.; Cao, Z.; Classon, M. and McKnight, S. L. 1995. Cascade regulation of terminal adipocyte differentiation by three members of the C/EBP family of leucine zipper proteins. Genes \& Development 9:168-181. https://doi. org/10.1101/gad.9.2.168

Zaini, M. A.; Müller, C.; de Jong, T. V.; Ackermann, T.; Hartleben, G.; Kortman, G.; Gührs, K. H.; Fusetti, F.; Krämer, O. H.; Guryev, V. and Calkhoven, C. F. 2018. A p300 and SIRT1 regulated acetylation switch of C/EBP $\alpha$ controls mitochondrial function. Cell Reports 22:497-511. https://doi.org/10.1016/j.celrep.2017.12.061

Zebisch, K.; Voigt, V.; Wabitsch, M. and Brandsch, M. 2012. Protocol for effective differentiation of 3T3-L1 cells to adipocytes. Analytical Biochemistry 425:88-90. https://doi.org/10.1016/j.ab.2012.03.005

Zhang, Y.; Jia, L.; Lee, S. J. and Wang, M. M. 2007. Conserved signal peptide of Notch3 inhibits interaction with proteasome. Biochemical and Biophysical Research Communications 355:245-251. https://doi.org/10.1016/j.bbrc.2007.01.151

Zhang, Y.; Repa, J. J.; Gauthier, K. and Mangelsdorf, D. J. 2001. Regulation of lipoprotein lipase by the oxysterol receptors, LXR $\alpha$ and LXR $\beta$. The Journal of Biological Chemistry 276:43018-43024. https://doi.org/10.1074/jbc.M107823200 